\title{
Brazilian green propolis hydroalcoholic extract as a therapeutic adjuvant to treat cutaneous leishmaniasis
}

\author{
Beatriz Carvalho Cunha ${ }^{1}$, Marina Barcelos de Mirandaㄹ, Luís Carlos Crocco Afonsoํㅜ, Sheila Rago Lemos Abreu², Míriam \\ Conceição De Souza Testasicca ${ }^{1}$, Gisele Rodrigues Da Silva ${ }^{3 *}$, Sandra Aparecida Lima De Moura ${ }^{1}$ \\ ${ }^{1}$ Department of Biological Sciences, Federal University of Ouro Preto, Campus Morro do Cruzeiro, Ouro Preto, 35.400-000 Minas Gerais, Brazil. \\ ${ }^{2}$ Nectar Pharmaceutical Ltda, Belo Horizonte, 30.130-151 Minas Gerais, Brazil. \\ ${ }^{3}$ Department of Pharmacy, Federal University of Ouro Preto, Campus Morro do Cruzeiro, Ouro Preto, 35.400-000 Minas Gerais, Brazil.
}

\section{ARTICLE INFO \\ Received on: 26/05/2020 \\ Accepted on: 30/07/2020 \\ Available online: 05/11/2020}

Key words:

Leishmania amazonensis,

propolis, macrophages.

\begin{abstract}
Cutaneous leishmaniasis is caused by Leishmania parasites. There are a limited number of drugs to treat the cutaneous leishmaniasis, and most of them cause severe adverse effects. Therefore, new therapeutic strategies to treat cutaneous leishmaniasis should be developed. In this study, a standardized Brazilian green propolis (BGP) hydroalcoholic extract (Cytopropolis ${ }^{\circledR}$, Nectar Pharma Brazil) was evaluated as a therapeutic adjuvant, aiming at the treatment of cutaneous leishmaniasis. The antileishmanial effects of different concentrations of BGP hydroalcoholic extract (500, 250, 125, $62.5,31.25,15.6,7.8$, and $3.9 \mu \mathrm{g} \mathrm{ml}^{-1}$ ) were determined in vitro against amastigotes and promastigotes and in a murine model of leishmaniasis. High concentrations of BGP hydroalcoholic extract $\left(500,250,125\right.$, and $\left.62.5 \mu \mathrm{g} \mathrm{ml}^{-1}\right)$ reduced the viability of promastigotes. All concentrations acted against amastigotes. BGP hydroalcoholic extract (500 and 250 $\mu \mathrm{g} \mathrm{ml}^{-1}$ ) decreased the number of promastigotes in macrophages. In addition, after 2 weeks of oral treatment, BGP hydroalcoholic extract $(250 \mathrm{mg} / \mathrm{kg} /$ day $)$ decreased the parasites and induced the macrophage infiltration in the lesion caused by the Leishmania amazonensis on the paw of mice. BGP hydroalcoholic extract may represent a therapeutic adjuvant to treat cutaneous leishmaniasis.
\end{abstract}

\section{INTRODUCTION}

Leishmaniasis is caused by Leishmania parasites. They are transmitted through the female phlebotomine sand fly (de Freitas et al., 2016; World Health Organization (WHO), 2016). Leishmaniasis presents four manifestations: visceral, cutaneous, mucocutaneous, and diffused (Kevric et al., 2015; Pearson and Sousa, 1996). About $95 \%$ of the cases of cutaneous leishmaniasis occur in Asia, Mediterranean basin, and Latin America. It has been described that $0.7-1.3$ million new infections occur annually all over the world (McGwire and Satoskar, 2014; World Health

\section{${ }^{*}$ Corresponding Author}

Gisele Rodrigues Da Silva, Department of Pharmacy, Federal University of Ouro Preto, Campus Morro do Cruzeiro, Ouro Preto, 35.400-000 Minas Gerais, Brazil.E-mail: giselersilva@ufop.edu.br
Organization (WHO), 2016). In Brazil, at least seven species of Leishmania parasites that cause cutaneous leishmaniasis are known, among them, Leishmania amazonensis presents relevance (Hepburn, 2003; Vale and Furtado, 2005).

Pentavalent antimonial drugs $\left(\mathrm{Sb}^{5+}\right)$ are administered to treat leishmaniasis. However, if there is no satisfactory response to this treatment, amphotericin B and pentamidine are administered as the second-choice therapeutic regimen (Gonzalez, 2013; World Health Organization (WHO), 2016). These drugs require parenteral administration for prolonged periods. Therefore, there are few available drugs for leishmaniasis treatment. In addition, these drugs have high toxicity and they may induce side effects, which compromise the effectiveness of the treatment (Freitas-Junior et al., 2012; Rajasekaran and Chen, 2015). Another problem frequently observed in antileishmanial therapy is the rate of relapses, in which parasites may again become detectable. In this case, they may become unresponsive to the first-choice drugs due to the 
parasite resistance (Carvalho and Ferreira, 2001). Considering this scenery, to develop therapeutic alternatives to treat leishmaniasis is mandatory, especially those derived from natural products.

Propolis is produced by honeybees (Apis mellifera) from flowers and plant's exudates, along with salivary secretions, pollen, and wax. According to Miranda et al. (2019), Baccharis dracunculifolia DC is the source of green propolis from Brazil. In Brazil and Japan, the Brazilian green propolis (BGP) has been extensively used not only as a therapeutic adjuvant to prevent diseases but also as an ingredient in food and beverages (RebouçasSilva et al., 2017). The BGP shows different phytochemical substances, including phenolic substances ( $p$-coumaric acid, artepillin C, and baccharin, among others), which act against several pathogenic organisms (Correa et al., 2019; Devequi-Nunes et al., 2018; Scatolini et al., 2018). The biological effects of green propolis from Brazil were also evidenced against Leishmania braziliensis and Leishmania infantum (Ayres et al., 2011; Ferreira et al., 2014; Pontin et al., 2008), suggesting its effective antileishmanial activity.

Considering the antileishmanial potential of BGP and the necessity of discovering new therapeutic alternatives to treat the cutaneous leishmaniasis, in this study, a standardized BGP hydroalcoholic extract (Cytopropolis ${ }^{\circledR}$, produced by Pharma Nectar, Minas Gerais state, Brazil) was investigated as a therapeutic adjuvant to assist in the treatment of the cutaneous leishmaniasis through its action against in vitro L. amazonensis amastigotes and promastigotes and in a murine model of leishmaniasis.

\section{MATERIALS AND METHODS}

\section{Brazilian green propolis hydroalcoholic extract}

BGP was produced in Caeté (Minas Gerais, Brazil), a city rich in native $B$. dracunculifolia (Asteraceae). BGP hydroalcoholic extract $\left(\right.$ Cytopropolis $\left.{ }^{\mathbb{R}}\right)$ was produced and standardized by Pharma Nectar ${ }^{\circledR}$, Belo Horizonte (Minas Gerais state, Brazil). BGP hydroalcoholic extract was solubilized in water in different concentrations: $3.9,7.8,15.6,31.25,62.5,125,250$, and $500 \mu \mathrm{g} \mathrm{ml}{ }^{-1}$.

\section{High performance liquid chromatographic (HPLC) analysis}

Two grams of BGP was extracted with $25 \mathrm{ml}$ of $80 \%$ ethanol under ultrasound for 5 minutes, water bath at $70^{\circ} \mathrm{C}$ for 30 minutes, and finally, ultrasound for 5 minutes. The solution was centrifuged at $10,000 \mathrm{~g}$ for 30 minutes, and the supernatant was collected. $8 \mathrm{ml}$ of $80 \%$ ethanol was added to $2 \mathrm{ml}$ of the supernatant, filtered by using $0.45 \mu \mathrm{m}$ membrane, and analyzed by HPLC method to identify and quantify the phytochemical compounds of BGP hydroalcoholic extract. HPLC/DAD analysis (Merck Hitachi) was carried out by using a reversed phase column (YMC-Pack ODS-A $4.6 \times 250 \mathrm{~mm}, 5 \mu \mathrm{m}$ ), at $40^{\circ} \mathrm{C}, 1 \mathrm{ml}$ minute $^{-1}$ flow mobile phase, and a gradient elution [water (solvent $\mathrm{A}$ ) and methanol (solvent B): starting from $30 \%$ of $\mathrm{B}(0-15$ minutes) and increasing to $90 \%$ of B (15-75 minutes), held at $90 \%$ of B (75-95 minutes), and then decreasing to $30 \%$ of $\mathrm{B}$ (95-105 minutes)].

\section{In vitro antileishmanial activity}

Leishmania amazonensis

Leishmania (Leishmania) amazonensis (L. amazonensis) strains (IFLA/BR/1967/PH-8) were proliferated at $25^{\circ} \mathrm{C}$ in Grace's
Insect Medium (Sigma-Aldrich, St. Louis, MO). This medium was supplemented with $10 \%$ fetal bovine serum (FBS-Cultilab, Campinas, São Paulo, Brazil), previously inactivated at $56^{\circ} \mathrm{C}$ for 30 minutes, containing $1 \mathrm{mM}$ L-glutamine (Gibco BRL, Grand Island, $\mathrm{NY}$ ) and 100 units/ml of potassium penicillin G (USB Corporation, Cleveland, $\mathrm{OH}$ ) and pH 6.5 (Grace's 10\% FBS medium).

Determination of L. amazonensis promastigote viability

Leishmania amazonensis promastigotes $\left(5 \times 10^{5}\right.$ parasites per well) were cultured in 96-well plates in Grace's 10\% fetal bovine serum (FBS) medium added to different and increasing concentrations of BGP hydroalcoholic extracts $\left(3.9-500 \mu \mathrm{g} \mathrm{ml}^{-1}\right)$. They were incubated for 24,48 , and 72 hours at $25^{\circ} \mathrm{C}$. The parasites were rinsed with Grace's 10\% FBS medium and incubated with $150 \mu \mathrm{l}$ of 3-[4,5-dimethylthiazol-2-yl]-2,5-diphenyltetrazolium bromide (MTT) $\left[1 \mathrm{mg} \mathrm{ml}^{-1}\right.$ in phosphate-buffered saline (PBS), pH 7.4] (Sigma Chemical, Saint Louis, CO). After 3 hours, the parasites were lysed with $100 \mu \mathrm{l}$ of isopropanol, and absorbance values were measured at $570 \mathrm{~nm}$ versus $630 \mathrm{~nm}$ using a microplate reader (BioRad, San Diego, CA). Absorbance on the control ( $L$. amazonensis promastigotes receiving no treatment) was set as $100 \%$, while the mean absorbance \pm standard deviation in contact with BGP hydroalcoholic extracts was calculated in relation to the control (Silva et al., 2015).

\section{Determination of L. amazonensis amastigote viability}

The axenic amastigote forms were obtained according to the method of Teixeira et al. (2002). Leishmania amazonensis promastigotes were proliferated for 7 days, until they reached the stationary growth phase. They were rinsed once in PBS pH 7.4 at $2,000 \mathrm{~g}$, for 10 minutes. Then, the parasites were grown in Grace's medium supplemented with 5\% FBS previously inactivated at $56^{\circ} \mathrm{C}$ for 30 minutes, $1 \mathrm{mM}$ of L-glutamine, and 100 units $\mathrm{ml}^{-1}$ of potassium penicillin $\mathrm{G}\left(\mathrm{pH} \mathrm{5.4)}\right.$ ) and incubated at $32^{\circ} \mathrm{C}$ for 7 days until complete transformation into amastigote-like forms.

Leishmania amazonensis amastigotes $\left(5 \times 10^{5}\right.$ parasites per well) were cultured in 96-well plates in Grace's $10 \%$ FBS medium and were added to different and increasing concentrations of BGP hydroalcoholic extracts $\left(3.9-500 \mu \mathrm{g} \mathrm{ml}^{-1}\right)$. They were incubated for 24,48 , and 72 hours at $32^{\circ} \mathrm{C}$. Leishmania amazonensis amastigote viability was established as described in the "Determination of L. amazonensis promastigote viability" section (Silva et al., 2015).

\section{Determination of macrophage viability}

Peritoneal macrophages were obtained from female C57BL/6 mice. The animals received an injection of 3\% sodium thioglycolate, and 4 days after the administration, the peritoneal cavity was washed with $10 \mathrm{ml}$ of the Roswell Park Memorial Institute 1640 medium (RPMI-1640 medium) (Gibco BRL, Grand Island, NY). Finally, the peritoneal macrophages were counted and adjusted to $5 \times 10^{5}$ cells per milliliter.

This procedure was approved by the Research Ethics Committee of the Federal University of Ouro Preto under the protocol numbers $2015 / 58$. Peritoneal macrophages $\left(5 \times 10^{5}\right.$ macrophages per well) were cultured in the 96-well sterile microplates in RPMI-1640 medium containing different concentrations of BGP hydroalcoholic extracts (3.9-500 $\left.\mu \mathrm{g} \mathrm{ml}^{-1}\right)$. They were incubated for 24,48 , and 72 
hours at $25^{\circ} \mathrm{C}$. Macrophage viability was established as indicated previously (Enrichment of L. amazonensis metacyclic promastigote forms section) (Silva et al., 2015).

Determination of antileishmanial activity of BGP hydroalcoholic extract against intracellular L. amazonensis amastigotes

Peritoneal macrophages $\left(6 \times 10^{5}\right.$ cells per well $)$ were cultured in 24-well plates, containing round glass coverslips, in RPMI-1640 medium. Macrophages were infected with $L$. amazonensis promastigotes in stationary phase in the proportion of 10: 1 and incubated for 24 hours at $37^{\circ} \mathrm{C}$. Then, macrophages were washed with PBS ( $\mathrm{pH} 7.4$ ) to eliminate the free L. amazonensis amastigotes. Macrophages were added to different and increasing concentrations of BGP hydroalcoholic extracts $\left(3.9-500 \mu \mathrm{g} \mathrm{ml}^{-1}\right)$. After 24, 48, and 72 hours, the RPMI-1640 was removed; the glass coverslips were fixed with methanol for 10 minutes and stained by Giemsa. The number of L. amazonensis amastigotes was counted in 200 macrophages in triplicate.

\section{In vivo antileishmanial activity}

Animals

Female C57BL/6 mice at 6-8 weeks of age, weighing 25-30 g, were obtained from the Center of Animal Facility in the Federal University of Ouro Preto (UFOP). Animals received food and water ad libitum at room temperature in storage conditions with 12 hours of light/dark cycles. The Ethics Committee in Animal Experimentation at UFOP approved the protocol (number 19/2011).

\section{Enrichment of L. amazonensis metacyclic promastigote forms}

Leishmania amazonensis promastigotes $\left(1 \times 10^{5}\right.$ parasites $/ \mathrm{ml}$ ) were cultured in 96-well plates in Grace's 10\% FBS medium. After 5 days in culture, the parasites were centrifuged at $1,540 \mathrm{~g}$ at $4^{\circ} \mathrm{C}$ for 10 minutes. Then, they were rinsed with PBS ( $\mathrm{pH}$ 7.4) for 3 times and resuspended in Dulbecco's Minimum Essential Medium (Sigma-Aldrich, St. Louis, MO). This suspension received $2 \mathrm{ml}$ of $10 \%$ Ficoll (Sigma-Aldrich, St. Louis, MO), and it was centrifuged at $1.070 \mathrm{~g}$ at $25^{\circ} \mathrm{C}$ for 15 minutes. The supernatant, rich in metacyclic promastigotes, was collected (Marques-da-Silva et al., 2008; Späth and Beverley, 2001). Leishmania amazonensis promastigotes were washed twice by using PBS ( $\mathrm{pH} 7.4$ ), and they were counted by the Neubauer chamber.

\section{Infection and treatment of mice}

C57BL/6 mice ( $n=12$ per group) were contaminated with $1 \times 10^{5}$ of L. amazonensis metacyclic promastigotes suspended in sterile PBS pH 7.4 through injection on the footpad $(40 \mu \mathrm{l} / \mathrm{paw})$. After 2 weeks of the infection establishment, the animals were divided into two groups: (1) infected mice receiving $100 \mu \mathrm{l}$ of $250 \mathrm{mg} / \mathrm{kg} /$ day of BGP hydroalcoholic extract by gavage; and (2) infected mice receiving $100 \mu \mathrm{l}$ of PBS pH 7.4 per day by gavage. Then, three parameters were analyzed after 2 weeks of treatment: (1) the development of lesions, which were measured daily by using a caliper (Afonso and Scott, 1993); (2) the parasite load on the infected paw, which was assessed by the limiting dilution method adapted by Marques-Da-Silva et al. (2005); and (3) the histopathology of infected paw. Animals were euthanized; paws were fixed with methanol/dimethyl sulfoxide solution $(80: 20)$ and then processed for paraffin inclusion. Blocks were cut into 4- $\mu \mathrm{m}$ thickness and stained with Hematoxylin and Eosin (H\&E). Histological sections were scanned by a JVC-TK 1270/JGB cam.

\section{Statistical analysis}

Data were analyzed by the GraphPad Prism v.5 program (GraphPad Software, San Diego, CA). Results were shown as the mean \pm standard deviation. All values were firstly submitted to the Kolmogorov-Smirnov, D'Agostino and Person, and Shapiro-Wilk for normality tests. Normal distribution values were investigated by one-way ANOVA followed by Tukey's post-test. Nonnormal distribution values were investigated by Kruskal-Wallis test followed by Dunn's post-test. Significant $p$-values were less than 0.5 .

\section{RESULTS AND DISCUSSION}

Effects of a standardized BGP hydroalcoholic extract (Cytopropolis $^{\circledR}$, Nectar Pharma Brazil) were evaluated as a therapeutic adjuvant to treat the cutaneous leishmaniasis caused by $L$. amazonensis. There is increasing interest in natural products that facilitate the healing process in pathological conditions without causing systemic adverse effects and present low cost. BGP hydroalcoholic extract, a natural beehive product, seems to fulfill these therapeutic and socioeconomic requirements (De Castro, 2001; Sforcin, 2007).

In Brazil, the $B$. dracunculifolia DC is an important source of BGP. The chemical constitution of BGP is equivalent to the composition of $B$. dracunculifolia DC exudates. The BGP hydroalcoholic extract comprises, among other phytochemical compounds, pinobankain-3-acetate $(0.534 \%)$, coumaric acid $(0.580 \%)$, baccharin $(1.787 \%)$, and artepillin C $(6.350 \%)$, as the major compound, as indicated in Table 1.

The chromatogram representative of the phytochemical compounds of BGP hydroalcoholic extract is shown in Figure 1.

The BGP hydroalcoholic extract is rich in biologically active compounds, including the prenylated phenylpropanoids, represented by baccharin, artepillin $\mathrm{C}$, and coumaric acid (Devequi-Nunes et al., 2018). However, the flavonoids present in the BGP hydroalcoholic extract, such as quercetin, kaempferol, pinocembrin, and galangin, even in minor concentrations than those from prenylated compounds, may also display an antileishmanial effect probably due to the following reasons: (1) the macrophage activation, leading to Leishmania killing due to the expression of reactive oxygen and nitrogen metabolites (Ferreira et al., 2014; Potin et al., 2008); (2) the inhibition of angiogenesis in infected and injured tissue, contributing to the anti-inflammatory response (Miranda et al., 2019); and (3) the expression of proinflammatory cytokines, such as tumor necrosis factor by macrophages, promoting the inflammatory resolution (Miranda et al., 2019).

The L. amazonensis promastigote viability in direct contact with different concentrations of BGP hydroalcoholic extract is shown in Figure 2. At 500, 250, 125, and $62.5 \mu \mathrm{g}$ $\mathrm{ml}^{-1}$ concentrations, BGP hydroalcoholic extracts decreased the viability of promastigotes as compared to the control $(p<$ $0.05)$. These BGP hydroalcoholic extracts $(500,250,125$, and 
Table 1. Phytochemical compounds of BGP hydroalcoholic extract: identification, wavelength of detection (nm), retention time (minutes), and quantitation $(\mathrm{mg} / \mathrm{g}$ and $\%)$

\begin{tabular}{|c|c|c|c|c|}
\hline Phytochemical compound & Wavelength of detection (nm) & Retention time (minute) & Assay (mg/g) & Assay (\%) \\
\hline Coumaric acid & 310 & 13,847 & 5.800 & 0.580 \\
\hline Rutin (quercetin-3-O-rutinoside) & 254 & 22,860 & 0.543 & 0.054 \\
\hline Pinobanksin & 289 & 34,287 & 0.704 & 0.070 \\
\hline Quercetin & 254 & 40,527 & 1.805 & 0.181 \\
\hline Kaempferol & 267 & 50,067 & 1.330 & 0.133 \\
\hline Apigenin & 267 & 51,480 & 0.104 & 0.010 \\
\hline Pinocembrin & 289 & 54,747 & 1.670 & 0.167 \\
\hline Pinobankain-3-acetate & 310 & 57,413 & 5.342 & 0.534 \\
\hline Chrysin & 267 & 60,533 & 1.014 & 0.101 \\
\hline Galangin & 267 & 62,113 & 0.577 & 0.058 \\
\hline Tectochrysin & 267 & 73,780 & 0.453 & 0.045 \\
\hline Artepillin C & 310 & 79,533 & 63.504 & 6.350 \\
\hline Baccharin & 289 & 87,080 & 17.873 & 1.787 \\
\hline
\end{tabular}

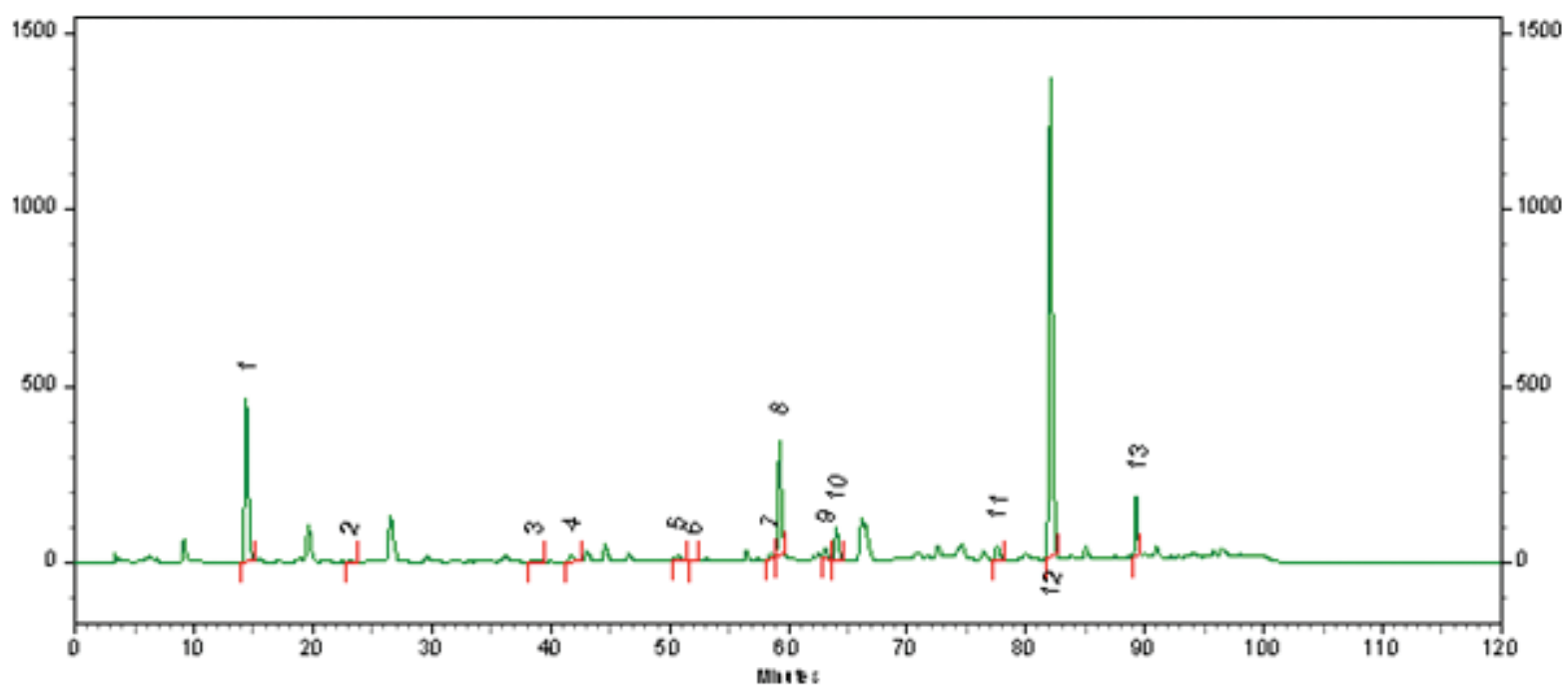

Figure 1. Phytochemical compounds of BGP hydroalcoholic extract. (1) Coumaric acid; (2) rutin (quercetin-3-O-rutinoside); (3) pinobanksin; (4) quercetin; (5) kaempferol; (6) apigenin; (7) pinocembrin; (8) pinobankain-3-acetate; (9) chrysin; (10) galangin; (11) tectochrysin; (12) artepillin C; (13) baccharin. Chromatographic conditions are as follows: reverse phase column (YMC-Pack ODS-A $4.6 \times 250 \mathrm{~mm}, 5 \mu \mathrm{m}$ ), at $40^{\circ} \mathrm{C}, 1 \mathrm{ml}$ minute ${ }^{-1}$ flow mobile phase, and a gradient elution [water (solvent A), methanol (solvent B): starting from $30 \%$ of B $(0-15$ minutes), augmenting to $90 \%$ of B (15-75 minutes), held at $90 \%$ of B (75-95 minutes), and finalizing to $30 \%$ of B (95-105 minutes)].
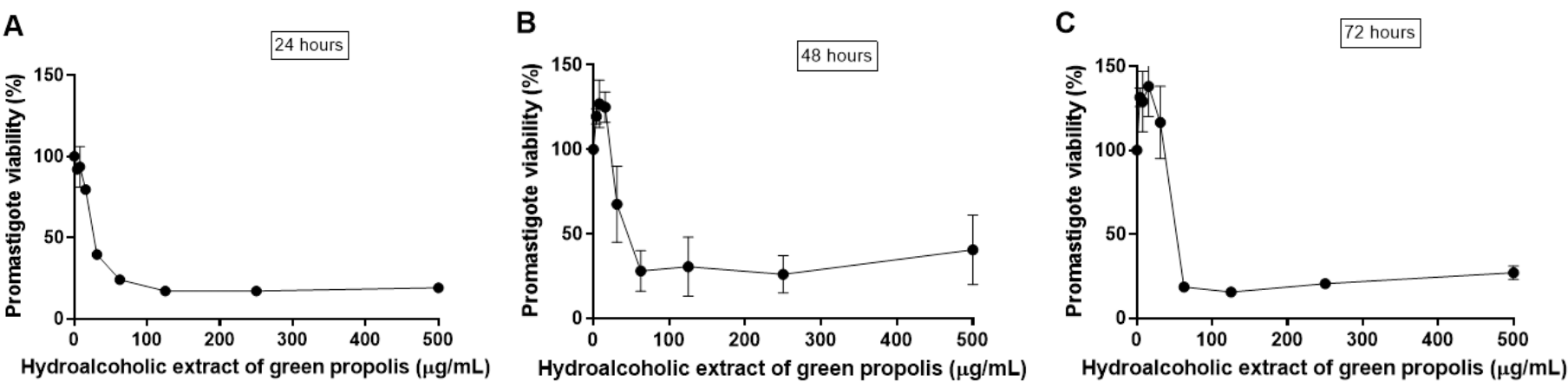

Figure 2. Leishmania amazonensis promastigote viability (\%) after (A) 24, (B) 48, and (C) 72 hours of direct contact with different and increasing concentrations of BGP hydroalcoholic extracts $\left(3.9,7.8,15.6,31.25,62.5,125,250\right.$, and $\left.500 \mu \mathrm{g} \mathrm{ml}^{-1}\right)$. Data were represented as mean \pm standard deviation three independent experiments). 
$62.5 \mu \mathrm{g} \mathrm{ml}^{-1}$ ) induced the progressive reduction of the parasite viability, leading to approximately $75 \%$ of lysis after 24 hours of exposition. On the contrary, the $3.9,7.8,15.6$, and $31.25 \mu \mathrm{g} \mathrm{ml}^{-1}$ concentrations of BGP hydroalcoholic extracts did not exhibit an antileishmanial effect against $L$. amazonensis promastigotes even after 72 hours of exposition. Therefore, these BGP hydroalcoholic extract concentrations $\left(3.9,7.8,15.6\right.$, and $\left.31.25 \mu \mathrm{g} \mathrm{ml}^{-1}\right)$ did not induce the significant reduction of promastigote forms when compared with the control $(p>0.05)$. By contrast, in some cases, the other concentrations led to increased parasite metabolism. Based on the parasite growth curves of parasites exposed to the different concentrations of BGP hydroalcoholic extract, none of these concentrations induced greater parasite proliferation when compared to control. Thus, the higher metabolism presented is not justified by a higher number of parasites in culture. Apparently, the propolis, in the mentioned concentrations, led to a greater metabolizing capacity of the parasite. Mosmann (1983) supported this hypothesis. According to his study, the amount of formazan generated per cell depended on the cell's energy metabolism level. This author demonstrated, in an experiment with lymphocytes, that activated cells produced 10 times more formazan per cell when compared to normal cells.

Potin et al. (2008) also investigated the BGP hydroalcoholic extract activity against $L$. amazonensis promastigotes. At 500 $\mu \mathrm{g} \mathrm{ml}^{-1}$, it promoted $79.3 \%$ of parasite lysis after 24 hours of treatment. This BGP hydroalcoholic extract was produced in Oliveira city, Minas Gerais, in Brazil, a city rich in B. dracunculifolia; and it had artepillin $\mathrm{C}$, as a major compound, as well as coumaric acid, drupanin, and caffeic acid, as chemical constituents. Although the natural sources obtaining the BGP hydroalcoholic extracts in this study and in Potin et al.'s study (2008) were identical, their geographic origins were different, inducing the differences between their chemical profiles. However, they showed similar antipromastigote activity, which may be associated with the action exerted by their chemical compounds, especially artepillin $\mathrm{C}$, which was capable of inducing morphological modification into promastigote forms of Leishmania (Silva et al., 2013). By contrast, the BGP hydroalcoholic extract produced in Cajuru city, São Paulo state in Brazil, a region rich in $B$. dracunculifolia, showed a phytochemical profile comprising isolated ursolic acid, uvaol, and hautriwaic acid lactone, among other substances. These compounds were active against $L$. donovani promastigotes (da Silva Filho et al.,
2009). Therefore, the antileishmanial activity of propolis might be associated with the effects of several substances, belonging to different phytochemical classes, and their complex synergism when in direct contact with the parasite.

The L. amazonensis amastigote viability in direct contact with different concentrations of BGP hydroalcoholic extract is shown in Figure 3. After 24 hours of exposition, 500, $250,125,62.5,31.25$, and $15.6 \mu \mathrm{g} \mathrm{ml}^{-1}$ concentrations of BGP hydroalcoholic extracts decreased the viability of amastigote forms $(p<0.05)$. In addition, after 48 and 72 hours, all concentrations of BGP hydroalcoholic extracts, including the lowest evaluated concentrations ( 7.8 and $3.9 \mu \mathrm{g} \mathrm{ml}^{-1}$ ), were capable of exerting antileishmanial effect against the $L$. amazonensis amastigotes ( $p$ $<0.05)$.

The amastigote-like forms were more susceptible to the BGP hydroalcoholic extract when compared to L. amazonensis promastigotes since even the lowest concentration of this extract exerted significant activity against the parasites. According to Ayres et al. (2011), prenylated and benzophenones are the main compounds associated with the inhibition of amastigotes. This information corroborated with our findings, since the BGP hydroalcoholic extract presented the artepillin $\mathrm{C}$, a prenylated substance, as the most abundant substance among the chemical compounds of this propolis. In addition, the higher susceptibility of amastigote-like forms to these substances can be explained by the fact that amastigotes and promastigotes differ in several biochemical properties, including proteinase, ribonuclease, adenine deaminase, peroxidase, and dehydrogenase activities. Moreover, they also differ due to the nitric oxide activity, nucleic acid synthesis, and glucose catabolism (Sereno and Lemesre, 1997).

Macrophages are the most important host cells for formation of Leishmania infection and permanence of parasites. Following promastigote internalization, multiplication and promastigote-to-amastigote differentiation occur, causing cellular injury (Podinovskaia and Descoteaux, 2015). However, as the macrophages are plastic cells prepared to homeostatic functions and to present the antigens, even in their infected state, they are activated (Liu and Uzonna, 2012). The activation by IFN- $\gamma$ induces the inflammation, leading to reactive oxygen species (ROS) production and antigen presentation. In addition, macrophages induce the formation of dihydronicotinamideadenine dinucleotide phosphate oxidase and Nlrp3 inflammasome
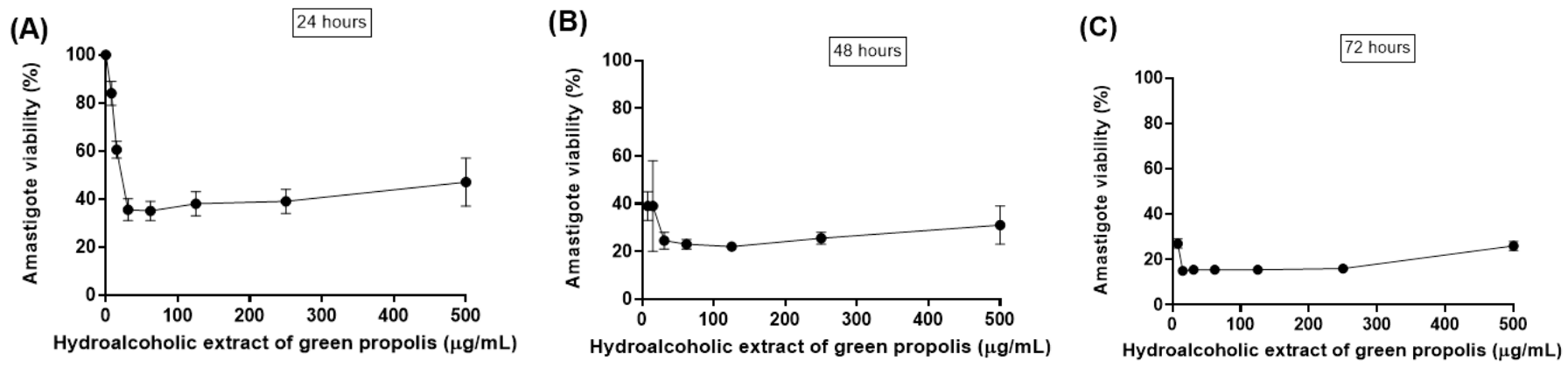

Figure 3. Leishmania amazonensis amastigote viability (\%) after (A) 24, (B) 48, and (C) 72 hours of direct contact with different and increasing concentrations of BGP hydroalcoholic extracts $\left(3.9,7.8,15.6,31.25,62.5,125,250\right.$, and $\left.500 \mu \mathrm{g} \mathrm{ml}^{-1}\right)$. Data were represented as mean \pm standard deviation (three independent experiments). 
complexes, producing ROS and reactive nitrogen intermediates. Finally, macrophages modulate the production of arachidonic acid and other proinflammatory mediators. As a result, the Leishmania growth can be impaired and/or inhibited (Podinovskaia and Descoteaux, 2015).

Considering the importance of macrophages to establish the host-parasite interaction and the multiple approaches used by infected and activated macrophages to eliminate the parasites, the murine peritoneal macrophages were selected to evaluate the cytotoxicity of BGP hydroalcoholic extract. The viability of macrophages exposed to $500,250,125,62.5,31.25,15.6,7.8$, and $3.9 \mu \mathrm{g} \mathrm{ml}^{-1}$ concentrations of BGP hydroalcoholic extract is shown in Figure 4. All the concentrations of BGP hydroalcoholic extract did not induce significant reduction of the macrophage viability when compared with the control at 24, 48, and 72 hours of experimentation $(p<0.05)$, suggesting the absence of cytotoxicity against this cell population.

In addition, antileishmanial activity of BGP hydroalcoholic extract against intracellular L. amazonensis amastigotes is shown in Figure 5. Among all the concentrations evaluated, only 500 and $250 \mu \mathrm{g} \mathrm{ml}^{-1}$ provided the reduction of the rate of infected macrophages $(p<0.05)$ at all experimentation periods. When treated with 500 and $250 \mu \mathrm{g} \mathrm{ml}^{-1}$, the percentage of infected cells was approximately $23 \%$ and $15 \%$, respectively, after 72 hours of exposition. As a consequence, these concentrations also provided the decrease in the quantity of intracellular amastigotes. When treated with 500 and $250 \mu \mathrm{g} \mathrm{ml}^{-1}$, the number of parasites was approximately 3 and 2, respectively, after 72 hours of direct exposition, evidencing the concentration-dependent antileishmanial activity of the BGP hydroalcoholic extract. Therefore, the BGP hydroalcoholic extract selectively eliminated the intracellular amastigotes without inducing impairment to host cells. The mechanism of Leishmania amastigote death may be related to the ROS production and diffusion in the macrophage, creating an antimicrobial environment that induces parasite killing (Olekhnovitch et al., 2014). Another possibility to explain the death of amastigotes is that constituents of BGP hydroalcoholic extract intensify the expression of cytokines evolved in the elimination of intracellular parasite. According to Marcucci (2000) and Trusheva et al. (2006), prenylated and benzophenones compounds from propolis play an important role through macrophage activation.

A murine model of leishmaniasis was applied to determine the efficacy of BGP hydroalcoholic extract to eliminate the L. amazonensis. After 2 weeks of infection, the animals were divided into two groups: (1) control group, receiving no treatment; (2) treated group, receiving $250 \mathrm{mg} / \mathrm{kg} / \mathrm{day}$ of BGP hydroalcoholic extract for 2 weeks. The lesions of animals of both groups measured approximately $0.3 \mathrm{~mm}$ in diameter; and the average lesion diameters showed no statistical difference ( $p$ $>0.05$ ). By contrast, the parasites on mice' paws of both groups showed statistical difference $(p<0.05)$, since the $L$. amazonensis metacyclic promastigote number in the animals receiving BGP hydroalcoholic extract was lower than that in the control animals (Fig. 6). In addition, the histopathological analysis revealed that the paw of treated animals exhibited an intense inflammatory infiltrate, diffusely distributed, and mainly composed of macrophages. The paw of control animals showed a mild inflammatory infiltrate. In both groups, the epidermis and dermis were completely preserved (Fig. 7). These findings indicated that the BGP hydroalcoholic extract induced the recruitment of macrophages to the site of lesion caused by L. amazonensis; and it also modulated the hostnonspecific immunity by macrophage activation, leading to the elimination of intracellular parasites (Orsini et al., 2016). The elimination of parasites by BGP hydroalcoholic extract may be explained by the following reasons: (1) stimulation of apoptosislike process in parasites (Vannier-Santos and De Castro, 2009); (2) stimulation of the expression of ROS, especially superoxide dismutase, which play an important role in the macrophage activation and in reduction of intracellular promastigotes (Novais et al., 2009; Rebouças-Silva et al., 2017). RebouçasSilva et al. (2017) also demonstrated that ethanolic and glycolic propolis extracts reduced the number of promastigotes in murine macrophages by regulating the oxidative stress response; (3) stimulation of the expression of IL-4 and IL-7 and downregulation of IL-10 expression. IL-4 is responsible for controlling the exacerbated inflammation, and it inhibits IL-10 production, a cytokine associated with the leishmaniasis progression (Dos Santos Thomazelli et al., 2017; Salhi et al., 2008; Yao et al., 2005).

In conclusion, this study provids biological evidence that the standardized BGP hydroalcoholic extract (Cytopropolis ${ }^{\circledR}$, Nectar Pharma, Brazil) displayed in vitro antileishmanial activity, since it was capable of reducing the viability of promastigotes at high concentrations $\left(500,250,125\right.$, and $\left.62.5 \mu \mathrm{g} \mathrm{ml}^{-1}\right)$ and amastigotes at all concentrations. In addition, at 250 and $500 \mu \mathrm{g}$ $\mathrm{ml}^{-1}$, BGP hydroalcoholic extract was capable of inhibiting the proliferation of amastigotes in infected macrophages without
(A)

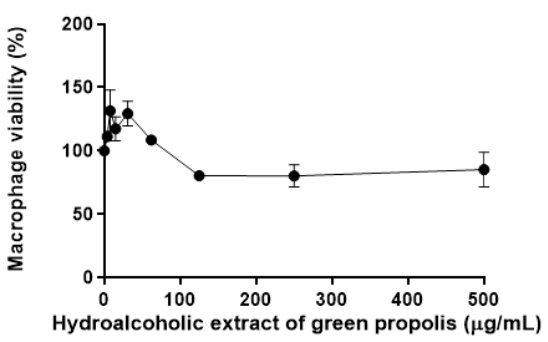

(B)

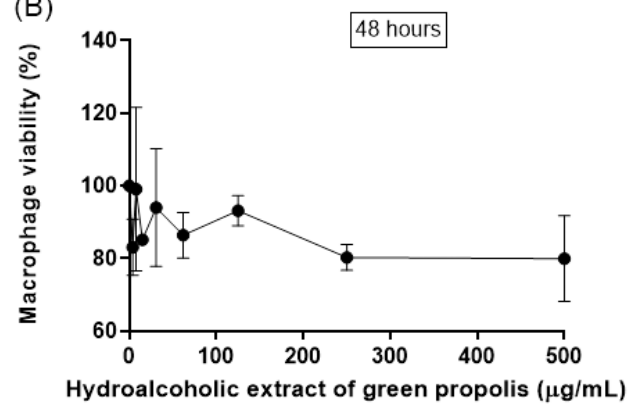

(C)

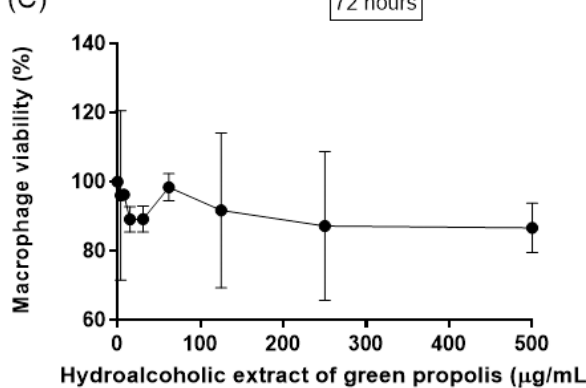

Figure 4. Macrophage viability (\%) after (A) 24, (B) 48, and (C) 72 hours of direct exposition to different concentrations of BGP hydroalcoholic extracts (3.9, 7.8, 15.6, $31.25,62.5,125,250$, and $500 \mu \mathrm{g} \mathrm{ml}^{-1}$ ). Data were represented as mean \pm standard deviation (two independent experiments). 


\section{4 hours}

(A)

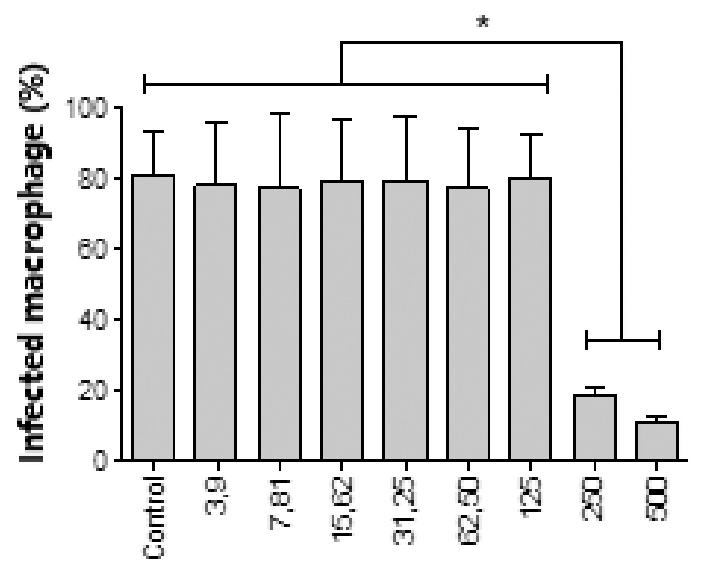

(B)

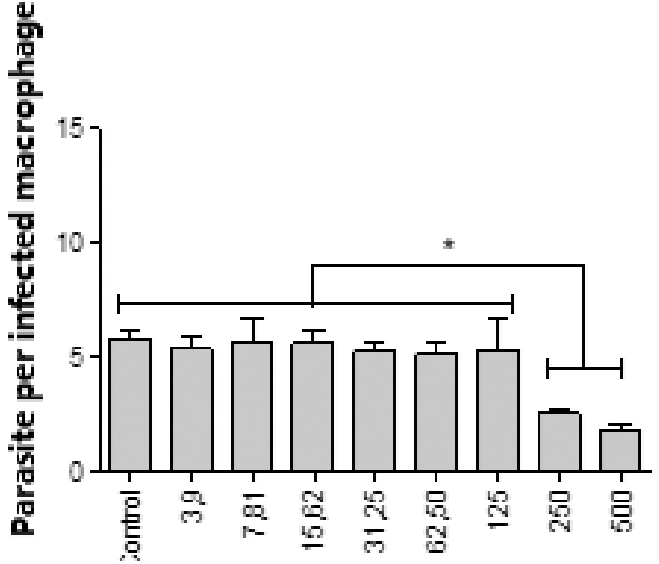

Hydroalcoholic extract of green propolis $(\mathrm{mcg} / \mathrm{mL})$

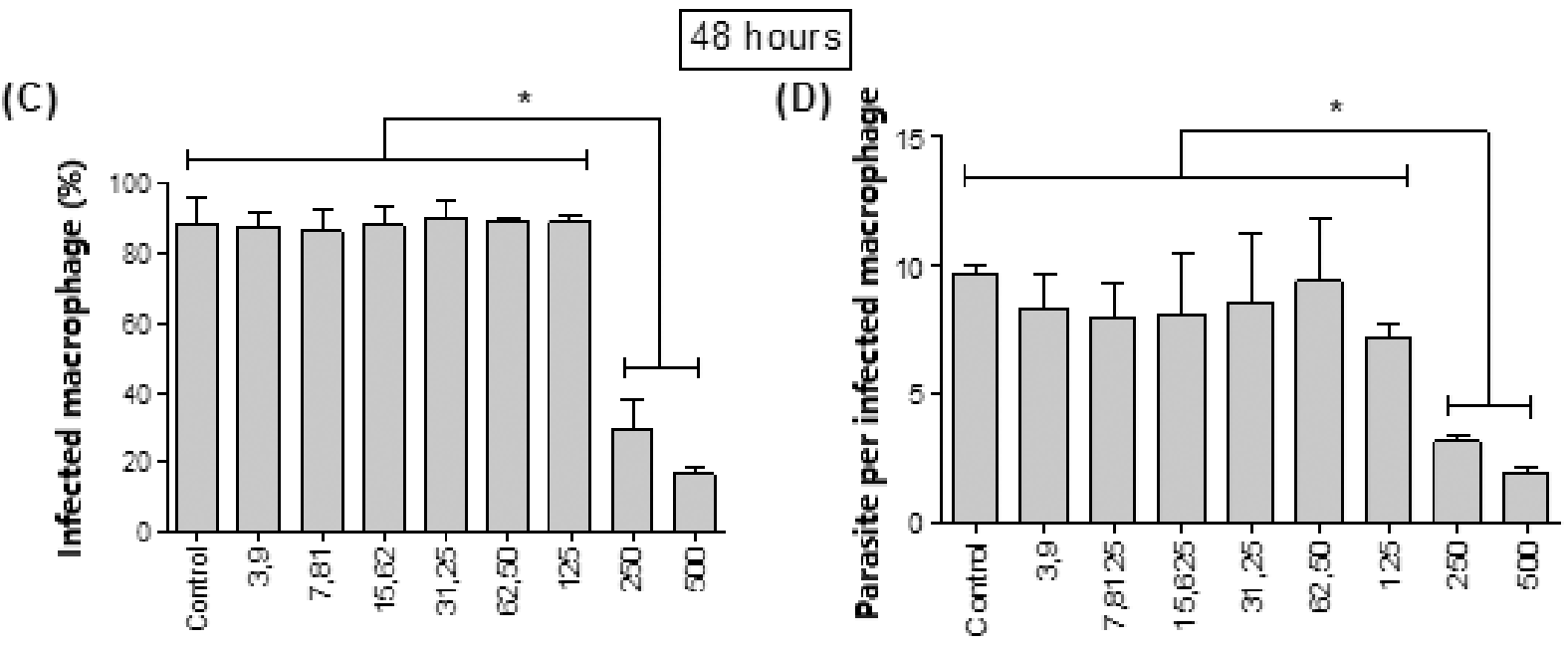

Hydroalcoholic extract of green propolis $(\mathrm{mcg} / \mathrm{mL})$

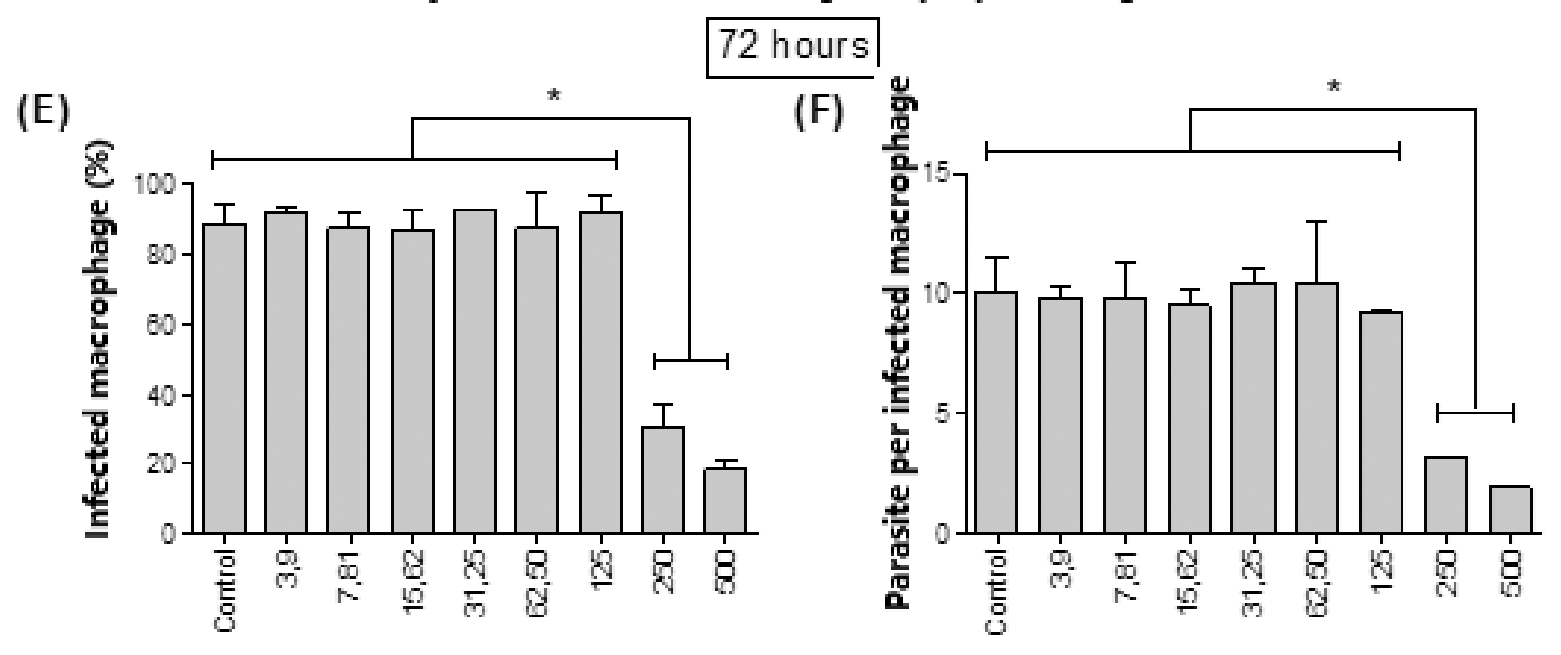

Hydroalcoholic extract of green propolis $(\mathrm{mcg} / \mathrm{mL})$

Figure 5. [(A), (C), and (E)] Percentage of macrophages infected by L. amazonensis amastigotes after 24, 48, and 72 hours, respectively, of treatment with different concentrations (3.6, 7.8, 15.6, 31.25, 62.5, 125, 250, and $500 \mu \mathrm{g} \mathrm{ml}{ }^{-1}$ ) of BGP hydroalcoholic extracts; [(B), (D) and (F)] number of $L$. amazonensis amastigotes in the macrophages after 24, 48, and 72 hours, respectively, of treatment with different concentrations $\left(3.6,7.8,15.6,31.25,62.5,125,250\right.$, and $\left.500 \mathrm{\mu g} \mathrm{m}^{-1}\right)$ of BGP hydroalcoholic extracts. Data were represented as mean \pm standard deviation (two independent experiments). * $p$-value $<0.05$. 


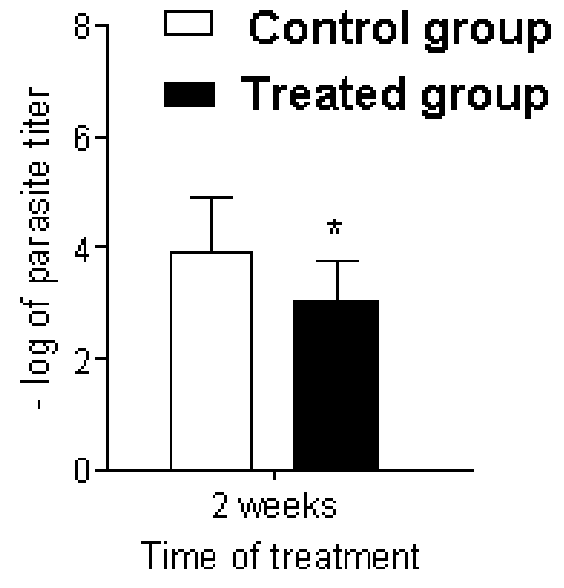

Figure 6. Leishmania amazonensis of metacyclic promastigote load of mice's paws. The control group received no treatment. The treated group received 250 $\mathrm{mg} / \mathrm{kg} /$ day of BGP hydroalcoholic extract for 2 weeks ( $n=12$ for each group). ${ }^{*} p=$ value $<0.05$.

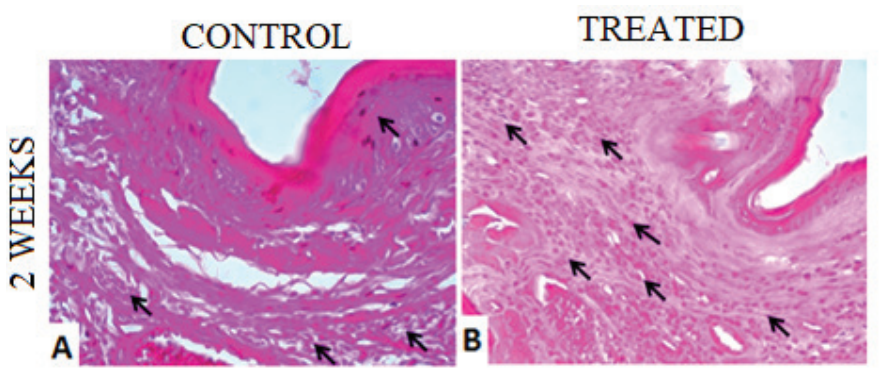

Figure 7. Histological sections of plantar cushion of C57BL/6 mice contaminated with $L$. amazonensis metacyclic promastigote. (A) Control group, receiving no treatment; (B) treated group, receiving $250 \mathrm{mg} / \mathrm{kg} /$ day of BGP hydroalcoholic extract for 2 weeks. Arrows indicate diffuse inflammatory infiltrate in the dermis. $4 \mu \mathrm{m}, 40 \mathrm{x}, \mathrm{H} \& \mathrm{E}$.

reducing viability of the host cells. In experimental leishmaniasis, the BGP hydroalcoholic extract induced the recruitment of macrophages in the lesion caused by the L. amazonensis and probably modulated the activation of these cells, which killed the intracellular parasites by oxidative and immunological processes. Finally, BGP hydroalcoholic extract may represent a potential therapeutic adjuvant to be orally administered to assist in the treatment of cutaneous leishmaniasis.

\section{ACKNOWLEDGMENTS}

The authors thank the financial support of the following institutions: CNPq (Brasília, Brazil), FAPEMIG (Minas Gerais, Brazil), CAPES (Brasília, Brazil), and UFOP (Minas Gerais, Brazil).

\section{CONFLICT OF INTEREST}

Authors declared that they have no conflicts of interest.

\section{FUNDING}

None.

\section{REFERENCES}

Afonso LC, Scott P. Immune responses associated with susceptibility of C57BL/10 mice to Leishmania amazonensis. Infect Immun. 1993; 61(7):2952-9.

Ayres DC, Fedele TA, Marcucci MC, Giorgio S. Potential utility of hyperbaric oxygen therapy and propolis in enhancing the leishmanicidal activity of glucantime. Rev Inst Med Trop São Paulo, 2011; 53:329-34.

Carvalho PB, Ferreira EI. Leishmaniais phytotherapy. Nature's leadership against an ancient disease. Fitoterapia, 2001; 72:599-618.

Correa FT, de Souza AC, de Souza Júnior EA, Isidoro SR, Piccoli RH, Dias DR, de Abreu LR. Effect of Brazilian green propolis on microorganism contaminants of surface of Gorgonzola-type cheese. J Food Sci Technol, 2019; 56(4):1978-87.

da Silva Filho AA, Resende DO, Fukui MJ, Santos FF, Pauletti PM, Cunha WR, Silva MLA, Gregório LE, Bastos JK, Nanayakkara NPD. In vitro antileishmanial, antiplasmodial and cytotoxic activities of phenolics and triterpenoids from Baccharis dracunculifolia DC (Asteraceae). Fitoterapia, 2009; 80(8):478-82.

De Castro SL. Propolis: biological and pharmacological activities. Therapeutic uses of this bee-product. Annual Rev Biomed Sci, $2001 ; 3: 49-83$

de Freitas EO, Leoratti FM, Freire-de-Lima CG, Morrot A, Feijó DF. The contribution of immune evasive mechanisms to parasite persistence in visceral leishmaniasis. Front Immunol, 2016; 7:153.

Devequi-Nunes D, Machado BAS, Barreto GA, Rebouças Silva J, da Silva DF, da Rocha JLC, Brandão HN, Borges VM, Umsza-Guez MA. Chemical characterization and biological activity of six different extracts of propolis through conventional methods and supercritical extraction. PLoS One. 2018; 4(13)(12):e0207676.

Dos Santos Thomazelli APF, da Silva SS, Tomiotto-Pellissier F, Panis C, Orsini TM, Cataneo AHD, Miranda-Sapla MM, Custódio LA, Tatakihara VLH, Bordignon J, Silveira GF, Sforcin JM, Pavanelli WR, Conchon-Costa I. Brazilian propolis promotes immunomodulation on human cells from American Tegumentar Leishmaniasis patients and healthy donors infected with $L$. braziliensis. Cell Immunol, 2017; 311:22-7.

Ferreira FM, Castro RAO, Batista MA, Rossi FMD, SilveiraLemos D, Frézard F, Moura SAL, Rezende SA. Association of water extract of green propolis and liposomal meglumine antimoniate in the treatment of experimental visceral leishmaniasis. Parasitol Res, 2014; 113:533-43.

Freitas-Junior LH, Chatelain E, Kim HA, Siqueira-Neto JL. Visceral leishmaniasis treatment: what do we have, what do we need and how to deliver it? Int J Parasitol Drugs Drug Resist. 2012; 2:11-19.

Gonzalez U. Cochrane reviews on neglected diseases: the case of cutaneous leishmaniasis. Cochrane Database Syst Rev, 2013; 3:ED000055. Hepburn NC. Cutaneous leishmaniasis: current and future management. Expert Rev Anti Infect Ther, 2003; 1(4):563-70.

Kevric I, Cappel MA, Keeling JH. New world and old world Leishmania infections: a practical review. Dermatol Clin, 2015; 33(3):579_ 93.

Liu D, Uzonna JE. The early interaction of Leishmania with macrophages and dendritic cells and its influence on the host immune response. Front Cell Infect Microbiol, 2012; 2:83.

Marcucci MC. Process to typing natural products. Requested patent. Brazilian National Institute for Intellectual Property, São José dos Campos, Brazil, 2000.

Marques-Da-Silva EA, Coelho EA, Gomes DC, Vilela MC, Masioli CZ, Tavares CAP, Fernandes AP, Afonso LCC, Rezende SA. Intramuscular immunization with p36(LACK) DNA vaccine induces IFNgamma production but does not protect BALB/c mice against Leishmania chagasi intravenous challenge. Parasitol Res, 2005; 98:67-74.

Marques-da-Silva EA, Oliveira JC, Figueiredo AB, Souza Lima Júnior D, Carneiro CM, Rangel Fietto JL, Crocco Afonso LC. Extracellular nucleotide metabolism in Leishmania: influence of adenosine in the establishment of infection. Microbes Infect, 2008; 10(8):850-7. 
McGwire BS, Satoskar AR. Leishmaniasis: clinical syndromes and treatment. QJM, 2014; 107(1):7-14.

Miranda MB, Lanna MF, Nascimento ALB, de Paula CA, de Souza ME, Felipetto M, Barcelos LS, Moura SAL. Hydroalcoholic extract of Brazilian green propolis modulates inflammatory process in mice submitted to a low protein diet. Biomed Pharmacother, 2019; 109: 610-20.

Mosmann T, Rapid colorimetric assay for cellular growth and survival: application to proliferation and cytotoxicity assays. J Immunol Methods, 1983;16(65)(1-2):55-3.

Novais FO, Santiago RC, Báfica A, Khouri R, Afonso L, Borges VM, Brodskyn C, Barral-Netto M, Barral A, de Oliveira CI. Neutrophils and macrophages cooperate in host resistance against Leishmania braziliensis infection. J Immunol, 2009; 183(12):8088-098.

Olekhnovitch R, Ryffel B, xFc, ller AJ, Bousso P. Collective nitric oxide production provides tissue-wide immunity during Leishmania infection. J Clin Invest, 2014; 124:1711-22.

Orsini TM, Kawakami NY, Panis C, Thomazelli APFS, Tomiotto-Pellissier F, Cataneo AHD, Kian D, Yamauchi LM, Júnior FSG, Lopes LGF, Cecchini R, Costa IN, Silva JJN, Conchon-Costa I, Pavanelli WR. Antileishmanial activity and inducible nitric oxide synthase activation by RuNO Complex. Mediators Inflamm, 2016; 2016:2631625.

Pearson RD, Sousa AQ. Clinical spectrum of leishmaniasis. Clin Infect Dis, 1996; 22(1):1-13.

Podinovskaia M, Descoteaux A. Leishmania and the macrophage: a multifaceted interaction. Future Microbiol, 2015; 10(1):111-29.

Pontin K, Silva AADS, Santos FF, Silva MLAE, Cunha WR, Nanayakkara NPD, Bastos JK, Albuquerque S. In vitro and in vivo antileishmanial activities of a Brazilian green propolis extract. Parasitol Res, 2008; 103(3):487-92.

Rajasekaran R, Chen YP. Potential therapeutic targets and the role of technology in developing novel antileishmanial drugs. Drug Discov Today, 2015; 20(8):958-68.

Rebouças-Silva J, Celes FS, Lima JB, Barud HS, de Oliveira CI, Berretta AA, Borges VM. Parasite killing of Leishmania (V) braziliensis by standardized propolis extracts. Evid Based Complement Alternat Med, 2017; 2017:6067172.

Salhi A, Rodrigues V Jr, Santoro F, Dessein H, Romano A, Castellano LR, Sertorio M, Rafati S, Chevillard C, Prata A, Alcaïs A, Argiro L, Dessein A. Immunological and genetic evidence for a crucial role of IL10 in cutaneous lesions in humans infected with Leishmania braziliensis. J Immunol. 2008; 180:6139-148.

Scatolini AM, Pugine SMP, de Oliveira Vercik LC, de Melo MP, da Silva Rigo EC. Evaluation of the antimicrobial activity and cytotoxic effect of hydroxyapatite containing Brazilian propolis. Biomed Mater, 2018; 30(13)(2):025010.
Sereno D, Lemesre JL. Axenically cultured amastigote forms as an in vitro model for investigation of antileishmanial agents. Antimicrob Agents Chemother, 1997; 41(5):972-76.

Sforcin JM. Propolis and the immune system: a review. J Ethnopharmacol, 2007; 113:1-14.

Silva JM, Antinarelli LMR, Ribeiro A, Coimbra ES, Scio E. The effect of the phytol-rich fraction from Lacistema pubescens against Leishmania amazonensis is mediated by mitochondrial dysfunction. Exp Parasitol, 2015; 159:143-50.

Silva SS, Thomé GS, Cataneo AHD, Miranda MM, Felipe I, Andrade CGTJ, Watanabe MAE, Piana GM, Sforcin JM, Pavanelli WR, Conchon-Costa I. Brazilian propolis antileishmanial and immunomodulatory effects. Evid Based Complement Alternat Med, 2013; 2013:673058.

Späth GF, Beverley SM. A lipophosphoglycan-independent method for isolation of infective leishmania metacyclic promastigotes by density gradient centrifugation. Exp Parasitol, 2001; 99(2): 97-103.

Teixeira MCA, Santos RJ, Sampaio RB, Carvalho LP, Santos WLC. A simple and reproducible method to obtain large numbers of axenic amastigotes of different Leishmania species. Parasitol Res, 2002; 88:963-8.

Trusheva B, Popova M, Bankova V, Simova S, Marcucci MC, Miorin PL, Pasin FR, Tsvetkova I. Bioactive constituents of brazilian red propolis. Evid Based Complement Alternat Med. 2006; 3:249-54.

Vale ECS, Furtado T. Leishmaniose tegumentar no Brasil: revisão histórica da origem, expansão e etiologia. An Bras Dermatol, 2005; 80(4):421-28.

Vannier-Santos MA, De Castro SL. Electron microscopy in antiparasitic chemotherapy: a (close) view to a kill. Curr Drug Targets, 2009; 10(3):246-60.

Ruiz-Postigo JA, Grouta L, Jaina S. Global leishmaniasis surveillance, 2017-2018, and first report on 5 additional indicators. World Health Organization (WHO), 2020; 95(25):265-80.

Yao Y, Li W, Kaplan MH, Chang CH. Interleukin (IL)-4 inhibits IL-10 to promote IL-12 production by dendritic cells. J Exp Med, 2005; 201:1899-903.

How to cite this article:

Cunha BC, De Miranda MB, Afonso LCC, Abreu SRL, Da Silva GR, Testasicca MCS, Moura SAL. Brazilian green propolis hydroalcoholic extract as a therapeutic adjuvant to treat cutaneous leishmaniasis. J Appl Pharm Sci, 2020; 10(11):124-132. 